University of Wollongong

Research Online

Faculty of Social Sciences - Papers (Archive) Faculty of Arts, Social Sciences \& Humanities

2015

The relevance of mindfulness practice for trauma-exposed disaster

researchers

Christine Eriksen

University of Wollongong, ceriksen@uow.edu.au

Tamara Ditrich

University of Sydney

Follow this and additional works at: https://ro.uow.edu.au/sspapers

Part of the Education Commons, and the Social and Behavioral Sciences Commons

Research Online is the open access institutional repository for the University of Wollongong. For further information contact the UOW Library: research-pubs@uow.edu.au 


\title{
The relevance of mindfulness practice for trauma-exposed disaster researchers
}

\begin{abstract}
This paper aims to raise awareness of vicarious trauma amongst disaster researchers, and suggests ways to prevent vicarious traumatisation from happening and/or reaching incapacitating levels. The paper examines the potential of mindfulness practice, grounded in Buddhist meditation, as a set of contemplation tools through which optimal level of functionality can be maintained or restored. The relevance of the emphasis in mindfulness on understanding suffering, non-attachment, non-judgement, and full participation in the present moment are related to the context of disaster research. The paper demonstrates the potential for increased researcher resilience through acknowledgement and understanding of impermanence, as well as skilful observation of external and internal phenomena in trauma without forming attachment to the pain and suffering.
\end{abstract}

\section{Keywords}

trauma, exposed, disaster, practice, researchers, relevance, mindfulness

Disciplines

Education | Social and Behavioral Sciences

Publication Details

Eriksen, C. \& Ditrich, T. (2015). The relevance of mindfulness practice for trauma-exposed disaster researchers. Emotion, Space and Society, 17 63-69. 
Eriksen, C. \& Ditrich, T. (2015) The relevance of mindfulness practice for trauma-exposed disaster researchers. Emotion, Space and Society, vol.17, pp.63-69

\title{
The Relevance of Mindfulness Practice for Trauma-Exposed Disaster Researchers
}

\begin{abstract}
This paper aims to raise awareness of vicarious trauma amongst disaster researchers, and suggest ways to prevent vicarious traumatisation from happening and/or reaching incapacitating levels. The paper examines the potential of mindfulness practice, grounded in Buddhist meditation, as a set of contemplation tools through which optimal level of functionality can be maintained or restored. The relevance of the emphasis in mindfulness on understanding suffering, non-attachment, non-judgement, and full participation in the present moment are related to the context of disaster research. The paper demonstrates the potential for increased researcher resilience through acknowledgement and understanding of impermanence, as well as skilful observation of external and internal phenomena in trauma without forming attachment to the pain and suffering.
\end{abstract}

\section{Keywords}

Disaster research; trauma; mindfulness; meditation; Buddhism; wildfire

\section{Introduction}

'Disaster shocks us out of slumber, but only skilful effort keeps us awake.' (Solnit 2009, 119)

Natural disasters, such as wildfires, are an endemic force in Australia and North America - a constant and ongoing part of their history, ecology and culture. As a growing number of people since the 1960s have chosen to live and work in fire- prone landscapes, an increasing number of scholars have focused on how people (re)act towards, cope with, and recover from direct personal experiences of such disasters (see, for example, Eriksen 2014; Enarson 2012; Jensen and McPherson 2008; Pyne 2006). The stories narrated by disaster survivors are often elaborate, filled with suspense and emotionally 
Eriksen, C. \& Ditrich, T. (2015) The relevance of mindfulness practice for trauma-exposed disaster researchers. Emotion, Space and Society, vol.17, pp.63-69

charged. It should therefore come as no surprise that researchers with whom these stories are shared could be vicariously traumatised. Yet, while there are extensive accounts and analysis of vicarious trauma amongst, for example, mental health professionals (Caruana 2010; Berceli and Napoli 2006; Hafkenscheid 2005) and emergency service personnel (McFarlane and Raphael 1984; Weiss et al. 1995; Beatson et al. 1998, 1999; Chopko and Schwartz 2009), there are no studies to date, to our knowledge, that explicitly deal with vicarious trauma amongst academic researchers who specifically work with individuals and communities directly impacted by natural disasters. This problem was also identified for research psychologists in the aftermath of the 9/11 terrorist attacks (Greenall and Marselle 2007).

This paper does not aim to clinically define symptoms, causes or degrees of vicarious trauma. Rather it aims to: a) raise awareness of a problem rarely acknowledged amongst disaster researchers, and b) suggest ways to prevent vicarious traumatisation from happening and/or reaching incapacitating levels by restoring and maintaining optimal levels of functionality through mindfulness practice, grounded in Buddhist meditation. This skill can be viewed as preventative or as a coping tool and is not a replacement for therapy or clinical intervention in cases where vicarious traumatisation has already developed into more serious clinical conditions. Rather, this paper emphasises preventative means for such serious conditions to develop in the first place through the focus in mindfulness on understanding, non-attachment, non-judgement, and full participation in the present moment. This can facilitate cultivation of "wise attention" within the research encounter through a deeper awareness, reflection, understanding and acceptance of ever-changing, interdependent processes of life. As such, it responds to struggles like those experienced by Ehrlich (2013) in the wake of the 2011 tripleearthquake-tsunami-nuclear-disaster in Japan, when the heartbreak of what she was witnessing made her wonder:

'In a dream I scratch dirt like a dog, panting and frantically working my paws, but the ground is hard-packed and refuses to open. As I travel around Tohoku, I try not to armour myself, but tell me, is there a way to catch grief and tear it open, examine the contents of its stomach? Death stalks us with its internal rain, shed from the same confining canopy that shelters sorrow.' (Ehrlich 2013, 45) 
Eriksen, C. \& Ditrich, T. (2015) The relevance of mindfulness practice for trauma-exposed disaster researchers. Emotion, Space and Society, vol.17, pp.63-69

This paper develops a set of contemplation tools, which can assist researchers to observe the feelings of external and internal trauma without forming attachment to the pain and suffering. It also provides grounds for development of deeper insight into the essence of human existence and nature.

\section{Vicarious trauma amongst trauma-exposed disaster researchers}

Lerias and Byrne $(2003,130)$ define vicarious traumatisation (also known as secondary traumatic stress) as 'the response of those persons who have witnessed, been subject to explicit knowledge of or, had the responsibility to intervene in a seriously distressing or tragic event'. It is an individual's psycho-emotional reactions caused by exposure to the traumatic experiences of others (Berceli and Napoli 2006). Symptoms include: re-experiencing the event, persistent avoidance (emotionally and behaviourally), increased anxiety and anger arousal, and impairment of optimal levels of functioning. Factors identified as predictors of the occurrence of trauma symptoms are: previous trauma history, prolonged exposure, psychological well-being, social support networks, age (resilience increases with time/life experience), gender (women more susceptible), education and socio-economic status (increases access and understanding of support networks), and coping styles (negative coping response increases anxiety symptoms) (Lerias and Byrne 2003). The lower intensity at which vicarious traumatisation can occur (compared with direct trauma) means many do not realise they are being affected:

'Victims may still be able to function relatively well in their life while still suffering its symptoms, ... [they] are often overlooked because their level of distress may not be significant enough to come to the attention of clinicians, ... [they often] suffer in silence until their distress escalates to visible levels.' (Lerias and Byrne 2003, 136-137)

Our journey towards recognising vicarious trauma amongst disaster researchers happened when the lead author after six years of ethnographic-style research with wildfire survivors, firefighters, and residents fearful of the potential threat of wildfire, observed a growing inability to manage seemingly inconsequential tasks both physically and mentally. The pain was simultaneously intangible and debilitating (ranging from nightmares, headaches, muscle/joint tension to internalised anxiety). The 
Eriksen, C. \& Ditrich, T. (2015) The relevance of mindfulness practice for trauma-exposed disaster researchers. Emotion, Space and Society, vol.17, pp.63-69

causes were subliminal - undercurrents in what was otherwise a busy everyday life. The thought of vicarious traumatisation seemed alien, as the pervading feeling during interviews with wildfire survivors had always been a profound sense of calm rooted in gratitude towards the participants for sharing their intensely personal experiences and emotions. Analysing and writing about these experiences seemed a suitable way to simultaneously process any internal reaction to these (often horror-filled) stories. This, it appears, was a vast underestimation of the potential accumulative effect of many years of indirect exposure to high-impact events.

It took direct exposure to a wildfire, however, for the lead author to reach a turning point in her journey towards managing stress and self-care. In October 2013 a ferocious, fast-moving wildfire swept through the Blue Mountains of New South Wales leaving a trail of devastation in its wake. With hindsight, this became a turning point, as it dawned on [her] while walking amongst the smouldering rubble, as part of the post-fire impact assessment team, that nothing about the devastation was a surprise. The ashen dust clouds, the blackened trunks and leaves frozen in the direction the fire storm travelled, survivors siftings through the rubble to find precious belonging, and the unspoken acknowledgement by all in the team of the horrors we might encounter - [she] felt like she had seen it all before, felt like she had been in that very scenario a hundred times before. In reality, however, [she] had not been exposed directly to the rawness immediately following a fire front before. The only reason this seemed familiar is because she had relieved this scenario hundreds of times during interviews with fire survivors and again and again and again during data analysis. This led to a hard but rewarding journey of exploring and witnessing grief, and getting to grips with how to better promote and facilitate self-care for disaster researchers. The second author, a Buddhist scholar who for four decades has been teaching the theory and practice of mindfulness to professionals working within various types of trauma, assisted this process.

This paper is an outcome of the discussions and collaboration between the two authors. It builds on the recognition that early detection through awareness of vicarious trauma is the key to combating the ripple effect of exposure to traumatic events, such as post-traumatic stress disorder (PTSD), depression and anxiety disorder (Caruana 2010; Lerias and Byrne 2003). Berceli and Napoli (2006) emphasise that this is particularly the case amongst professionals who persistently work with 
Eriksen, C. \& Ditrich, T. (2015) The relevance of mindfulness practice for trauma-exposed disaster researchers. Emotion, Space and Society, vol.17, pp.63-69

traumatised populations, as the prolonged exposure can potentially compromise their own health and well-being. Their advice to health care professionals of learning and practicing some form of mindfulness stress-reduction program is equally apt for academic researchers who work with disaster survivors, and the inherent vicarious trauma this exposes them to. This advice aligns with Garland et al.'s $(2009,37-38)$ proposal that:

'The mechanism allowing one to shift from stress appraisals to positive reappraisals involves the metacognitive mode of mindfulness, a mode in which thoughts are experienced as transient, psychological events rather than reflections of absolute reality. The practice of mindfulness may facilitate and strengthen this capacity for positive reappraisal'.

This capacity for positive reappraisal aligns with the notion of 'emotional illiteracy', which Greenspan (2003, xii) argues 'has less to do with our inability to subdue negative emotions than it does with our inability to authentically and mindfully feel them' (see also Williams et al. 2007). Before the potentials of mindfulness practice in the context of vicarious trauma are explored further, it is important to introduce the concept of mindfulness itself — from its origins in ancient Buddhist traditions to newer interpretations, developed in the last few decades.

\section{The roots of mindfulness}

The term 'Buddhism' refers to a rich and diverse spiritual tradition, which encompasses philosophy, psychology, ethics, meditation, and a spectrum of practices and beliefs (Gethin 1998, 1-3). Buddhism may be viewed as a philosophy of life rather than as a religion or alternatively, as a non-theistic religion since there is no Creator in Buddhism. Instead, the universe is assumed to have always existed, perpetually emerging and dissolving, dependent solely on ever-changing causes and conditions. Although most traditions have regarded meditation as an important or even central component of Buddhist practice, only since the $20^{\text {th }}$ century has the promotion of meditation expanded widely and it is today often considered to be the very essence of Buddhism (McMahan 2008, 183214). These new developments allowed mindfulness to be applied in new areas and secular environments and eventually to become detached from the Buddhist tradition itself. 
Eriksen, C. \& Ditrich, T. (2015) The relevance of mindfulness practice for trauma-exposed disaster researchers. Emotion, Space and Society, vol.17, pp.63-69

Mindfulness (sati in Pali; ${ }^{1}$ smrti in Sanskrit) is one of the main methods of meditation that has been situated at the core of Buddhist meditation practices since its earliest beginnings more than 2,500 years ago. In early Buddhist textual records, the word mindfulness (sati) commonly refers to awareness, accompanied by clear comprehension, of moment-to-moment mental and physical processes. Mindfulness is frequently described as presence, wakefulness or clear cognition, which is guarding the senses from unskilful reactions to sensory inputs (mental and physical) (Buddhaghosa 1956, 141).

Buddhism distinguishes several concepts related to mindfulness (Ditrich 2013). Firstly, the Pali term manasikara, commonly translated as awareness or attention, is presented in Buddhist psychology (Abhidhamma) as a mental component. It acts as the bare cognition of an object before it is identified and conceptualized in the process of cognition (Bodhi 1993, 81). Attention (manasikara) is present in any mental states, either skilful (e.g. compassion, kindness, wisdom) or non-skilful (e.g. anger, fear, greed). When attention is accompanied by understanding of what is skilful or wholesome (kusala) and what is unskilful (akusala) it is called wise attention (yoniso manasikāra). Wise attention facilitates the development of mindfulness and wisdom - the two factors which are, according to Buddhist teachings, essential on the path to spiritual liberation (Analayo 2006, 58). Hence there is a clear distinction between bare attention and mindfulness: attention occurs with any states whereas mindfulness accompanies only skilful mental states. When mindfulness (sati) arises together with clear comprehension and diligence, and when one is (temporarily) free from desires and aversions, it is called right mindfulness (samma sati) (Analayo 2006, 49). Right mindfulness is strongly linked to the ethical and soteriological aspects of the doctrine of Buddhist philosophy: mindfulness protects the mind from reacting with desire and aversion and thus prevents reactive suffering. It facilitates, in conjunction with clear comprehension, the development of wisdom that eventually leads to freedom

\footnotetext{
${ }^{1}$ Interpretations of mindfulness that have evolved in modern Buddhism very frequently refer back to Theravada sources. This overview of the roots of mindfulness therefore draws on the Theravada Buddhist canon, with the technical terms for mindfulness and the related concepts provided in Pali (in brackets), the language of the earliest Buddhist canon (Ditrich 2013). Due to technical issues, all the Pali words in this paper are transliterated without diacritical marks.
} 
Eriksen, C. \& Ditrich, T. (2015) The relevance of mindfulness practice for trauma-exposed disaster researchers.

from suffering (dukkha) and negative responses to life, such as anger, fear, grief, clinging.

Furthermore, mindfulness is presented as a foundation for moral and ethical growth, which is expressed in blossoming of wisdom and compassion, in relation to oneself, other beings and the environment.

\section{The Four Noble Truths}

Mindfulness is an indispensable component of the structural foundations of Buddhist teachings, commonly explicated through the paradigm of the four noble truths, which integrate ethical, soteriological and pragmatic aspects (Sumedho 1992). In Buddhist philosophy, the four noble truths are closely linked to mindfulness (Ditrich 2013).

The first truth - unsatisfactoriness of existence $(d u k k h a)$ - states that all living beings encounter physical and mental suffering due to clinging to pleasant, and aversion to unpleasant, experiences. Although physical pain is an inevitable experience, it is only linked to suffering when we react to the pain unskilfully (with, for example, anger, fear or aversion). This reaction to the pain is conditioned by an inability to understand and accept the impermanence of all phenomena of life. Buddhism teaches that it is through mindfulness that suffering is understood, alleviated, overcome and eventually transcended. Mindfulness facilitates direct intuitive insight (called wisdom) into the ever-changing, conditioned nature of all phenomena from moment to moment. It facilitates understanding that everything is interconnected and that there is no separate permanent entity, such as a self, separated from others, with absolute control over processes and events of life.

The second truth emphasises that the cause of unsatisfactoriness and suffering is attachment (tanha). It is by clinging to pleasant and by averting unpleasant experiences, which are conditioned by desires, fear, aversion and ignorance, that we experience suffering. Here the role of mindfulness is crucial yet again: it is mindfulness that discontinues and prevents negative responses and mental states, through recognition and understanding of attachment and clinging.

The third truth shows the end of suffering as liberation or enlightenment (nibbana). By transforming consciousness, we gradually free ourselves from clinging, ignorance and suffering. This freedom is 
Eriksen, C. \& Ditrich, T. (2015) The relevance of mindfulness practice for trauma-exposed disaster researchers.

realised through the practice of meditation, which cultivates skilful mental qualities, the most important among them being mindfulness.

The fourth truth focuses on the path to freedom from suffering - the noble eightfold path (ariyo attangiko maggo). The path is comprised of eight interrelated components, encompassing wisdom (panna), ethics (sila) and meditation (samadhi). Here mindfulness has a special role as the condition for the development of wisdom, which, in this context, refers to insight into the nature of all physical and mental phenomena, i.e. impermanence, unsatisfactoriness and absence of an intrinsic permanent self.

To summarise, Buddhist teachings situate mindfulness and wisdom as essential components that facilitate liberation from delusion, suffering and the related negative mental states (e.g. anger, fear, greed). When these are absent, it is postulated that thoughts and consequently, speech and actions, are skilful and wholesome (e.g. compassionate, kind), rooted in generosity, empathy and wisdom. Hence mindfulness is situated at the core of the ethical framework of Buddhist philosophy.

\section{The practice of mindfulness}

Buddhist meditation encompasses two main types of closely related practices. The first type is called calm meditation (samatha), which generates calmness and prevents — at least temporarily — negative mental states by concentrating on one select object for a period of time. Among various objects chosen for practise of calm meditation, one of the most common, after the breath, is the practice of loving kindness (metta). In this practice, the meditator cultivates systematically, through regular practice, loving thoughts, by consciously wishing peace, happiness and well-being to oneself and all other living beings. Loving kindness meditation develops increasingly open and positive mental states, encompassing all-inclusive kindness and empathy towards oneself and others. It thereby fosters numerous benefits such as calmness, happiness, generosity and well-being. In Buddhist traditions it is often recommended as a practise to be undertaken in conjunction with mindfulness.

The other type of meditation is called insight meditation (vipassana). Here the meditator practices mindfulness of all physical and mental phenomena from moment to moment without reacting, trying 
Eriksen, C. \& Ditrich, T. (2015) The relevance of mindfulness practice for trauma-exposed disaster researchers. Emotion, Space and Society, vol.17, pp.63-69

to change or control them, and without responding with desire or aversion. In this practise, the meditator gradually develops direct insight or intuitive understanding of all physical and mental phenomena as momentarily changing, and that there is no need to (personally) identify with them. The practice leads to insight into impermanence, interconnectedness and the conditioned nature of all phenomena and processes. This insight arises together with an intuitive understanding that it is not possible to control the ever-changing flow of phenomena and processes (which we call life). Attempts to be in control in all circumstances therefore lead to suffering. Hence suffering is preventable and not an inevitable response to life's uncertainties. Through mindfulness the meditator understands that although best intentions and consequent actions are important in any given situation, they are not the only condition for that situation to occur. Rather, every moment is the result of innumerable, everchanging processes and conditions that are beyond "control". Such insights lead to freedom from clinging and other negative states that cause suffering, and instead generate compassion and empathy. This freedom is viewed in Buddhism as transformation of consciousness, which amounts to liberation from suffering.

\section{New interpretations of mindfulness}

Today, mindfulness is no longer only a major component of Buddhist praxis. In the last few decades it has become ubiquitous, expanding worldwide, entering new contexts and taking on new roles (Ditrich 2013). Mindfulness is widely applied in, for example, psychotherapy, the corporate world, schools, wellness industries, and as a tool to enhance well-being at work (Follette et al. 2006; Germer et al. 2005). It is also taught to wildland fire fighters as a form of High Reliability Organizing (Thomas 2008) and even to military personnel (Watson 2013). It was Kabat-Zinn (2013) who largely contributed to the expansion of mindfulness in therapeutic environments with his initial eight-week program "Mindfulness Based Stress Reduction” (MBSR) in 1979. Since the 1980s, this program and many others derived from it have been developed and expanded worldwide. Among the prominent therapeutic programs, drawing from MBSR, is "Mindfulness Based Cognitive Therapy” (MBCT), which was developed in the 1990s as an intervention program, specifically designed for prevention of 
Eriksen, C. \& Ditrich, T. (2015) The relevance of mindfulness practice for trauma-exposed disaster researchers. Emotion, Space and Society, vol.17, pp.63-69

depression relapse and has shown significant positive outcomes, both as a preventative and therapeutic method (Segal, Williams and Teasdale 2013).

The last two decades have seen increasing research on the benefits of mindfulness, indicating numerous benefits of mindfulness-based therapies (Eifert and Forsyth 2005) and its positive effects on the brain and immune system (Davidson 2003). Being a relatively new field in the Western world, such research of mindfulness has usually applied methods used in medicine or social sciences and rarely phenomenological approaches (Petitmengin 2006). Hence, methodological questions arguably still require more attention (Bishop 2002; Baer 2013).

In the newer domains, mindfulness has been interpreted in new ways. It is most commonly presented as 'the awareness that emerges through paying attention on purpose, in the present moment, and nonjudgementally' (Kabat-Zinn 2003, 145). It is perceived as a tool in the pursuit of greater well-being, adaptability, happiness and life satisfaction, which reflects modern societal aims, such as personal satisfaction, self expression, self fulfilment, and self maintenance (Ditrich 2013). This view funnels the purpose of mindfulness practice into 'the ability to make adaptive decisions about handling difficult and problematic situations as they arise, as well as increased enjoyment of pleasant moments' (Baer and Krietemeyer 2006, 10).

In contrast, Buddhist mindfulness practice seeks freedom from any form of desire or attachment. In Buddhist traditions, the states of happiness and peace, which accompany various stages in meditation, are the side effects of the practice but not the goals. In Buddhism, mindfulness is embedded in ethics. It is viewed as the main tool to distinguish between skilful and unskilful mental states, and it is often described as protection from harmful (mental and physical) responses. In ancient texts mindfulness is compared to the gate-keeper of a town who allows only skilful and harmless people to enter. Its role is to guard the senses and recognise which mental states are skilful and consequently may be allowed to enter consciousness (and which are not) (Bodhi 2000, 1252-1253).

In the light of the new interpretations of mindfulness, it may be asked whether some of its components or aspects have been lost in translations (Gethin 2013). Since 2010 several studies have emerged discussing the relationship between the so-called "secular" and Buddhist versions of mindfulness (Williams and Kabat-Zinn 2013). Transplantation of mindfulness from its Buddhist soil into new 
Eriksen, C. \& Ditrich, T. (2015) The relevance of mindfulness practice for trauma-exposed disaster researchers.

environments has been approached in many ways, for example, as a distortion of traditional Buddhist meditation, as a skilful way of providing initial steps on the Buddhist path - a view recently adopted by Kabat-Zinn (2013), or as a method which has been stripped of its unnecessary Buddhist "cultural baggage" while retaining its useful essence (Gethin 2013, 265). Whatever approach chosen, the question remains: what has been lost in translation? It can be argued that viewing mindfulness primarily as a method for enhancement of well-being may reduce its breath and depth in developing deeper enquiry into human consciousness and its potentials (Ditrich 2013). From a traditional Buddhist perspective, it is the power of mindfulness that facilitates development of wise attention and deep insight into the impermanent nature of mental and physical processes, and only such an understanding leads to the cessation of suffering. Suffering is thus the starting point for development of mindfulness, which in turn acts as prevention and eventually leads to liberation from suffering.

\section{Mindfulness practice and the processing of vicarious trauma}

Analysis of the community cohesion that often arises in disaster provides insight into interesting overlaps between disaster and religion:

'Buddhism, for example, teaches that suffering comes from attachment, including attachment to past pains and future outcomes and to a sense of a separate self. Disaster encourages nonattachment to material goods as well as to past and future, or rather less attachment to abstractions and objects and more to other beings and states of being. People are set loose in an absorbing present of intense uncertainty. ... Indeed, disaster could be called a crash course in Buddhist principles of compassion for all beings, of non-attachment, of abandoning the illusion of one's sense of separateness, of being fully present, of awareness of ephemerality, and of fearlessness or at least aplomb in the face of uncertainty.' (Solnit 2009, 115-118)

These remarkable overlaps point to the potential for processing first-hand and secondary exposure to disaster with the aid of Buddhist mindfulness practice. From the perspective of mindfulness practice (as outlined above), traumatic situations, including vicarious trauma, may be viewed as circumstances 
Eriksen, C. \& Ditrich, T. (2015) The relevance of mindfulness practice for trauma-exposed disaster researchers.

for enhanced growth. In Buddhist terms, they can be experienced as conditions for the development of wisdom, non-attachment and compassion.

By penetrating under the surface appearance of objects (e.g. grief, flames or ruins), mindfulness observes the objects' characteristics, and reveals that they are the same for all conditioned phenomena. All is impermanent. This is significant in the context of disaster and research, as contemporary society tends to focus on the effects of disaster solely as trauma. For example, impacted individuals tend to be labelled as 'victims' instead of placing an equal focus on the post-traumatic growth potential, which can result from disaster and a view of individuals as 'survivors' (Eriksen 2014; Chopko and Schwartz 2009). Solnit $(2009,118)$ argues that the 'twin implications' of this one-sided outlook on trauma are 'that we are not supposed to suffer or that in our frailty we are not merely damaged, but only damaged by suffering. If suffering is a given, as it is for most religions, then the question is more what you make of it rather than how you are buffered from it altogether'.

Traumatic experiences reveal in acute, obvious and challenging ways the impermanent nature of life (environmentally, structurally, socially, etc.). They provide insight into how suffering arises due to clinging and expectations that cannot be met. Such experiences challenge the idea of the existence of a permanent independent person who is in control of life. Such insight can be liberating when it negates preconceived ideas about how life should be when facing uncontrollable circumstances, such as natural disasters or death. Hence, a traumatic experience can be viewed by a mindfulness practitioner as empowering through wise and compassionate acceptance of ever-changing processes and phenomena as impermanent. This applies to emotional phenomena, such as fear, grief and pain, as well as the matchstick remains of a forest or a burnt-out house. According to Buddhist teachings, it is from this position only that wise action can be performed, appropriate to any given circumstance. This is where mindfulness can help disaster researchers exposed directly or vicariously to trauma.

\section{Contemplation tools}

'Turning away and touching are both wrong ... For it is like a massive fire ... You cannot turn away from fire. You cannot hold it, either. You have to turn toward it, not knowing what it 
Eriksen, C. \& Ditrich, T. (2015) The relevance of mindfulness practice for trauma-exposed disaster researchers.

will bring, with your shovel or fire hose or simply with your attention.' (Busch 2011, 219)

In traumatic and post-traumatic situation, the practice of mindfulness, in the context of the four truths, can be viewed as a platform for development of wise and compassionate intentions and actions. It is through mindfulness that the suffering of others and oneself can be understood, abandoned, experienced, and cultivated wholesomely (Harvey 2013). The four truths can be used initially as tools for contemplation, with a reflective pattern that sustains the development of a reflective mind. This set of contemplation tools may enable researchers to identify and observe the feelings of external and internal trauma without forming attachment to the pain and suffering. The first truth on unsatisfactoriness of existence is faced directly in trauma. A skilful practitioner of mindfulness is able to avoid personally identifying with the suffering by accepting the change and suffering caused by, for example, a wildfire. Instead acknowledgement of impermanence and the conditioned nature of all phenomena enable the practitioner to embrace suffering with kindness towards oneself and others involved.

This embracement of suffering $(d u k k h a)$ is counter-intuitive in the context of Western science, as the mind thinks dualistically in terms of separate polarities. The logic of change occurring naturally with acceptance, is eloquently explained by Lumiere (2003, 251-252):

Many people think that if they accept things as they are, they will never change. Yet the acceptance or surrender that I am speaking of here is the power that truly transforms.... This truth cannot be fully understood by the mind; it can only be revealed through direct experience. And so, when clients relax their impulse to get rid of painful sensations or feelings and simply be present with them, they discover for themselves that their discomfort effortlessly dissolves or transforms over time.... When it comes to healing trauma, however, additional skills may be required... When we have experienced trauma, it tends to pull us out of the here and now into there and then. It returns us to repetitive reexperiencing or re-enactment of the past trauma. ... Healing trauma usually requires a skilful method that can facilitate being present with the nervous system's experience of trauma in the body. ... When we are conscious of awareness, and our trauma arises, we are 
Eriksen, C. \& Ditrich, T. (2015) The relevance of mindfulness practice for trauma-exposed disaster researchers. Emotion, Space and Society, vol.17, pp.63-69

not identified with it; we are not fixated and therefore no longer at the effect of it. There is naturally a being present with, or letting be, which allows a relaxation of the contracted, traumatic energy. Thus there is a synergy between the conscious recognition of awareness, which facilitates a skilful method, and the method, which facilitates being present with trauma. The synergy results not only in the healing of trauma, but can also result in liberation from suffering itself.

Experience of loss in trauma can also enhance insight into the nature of attachment - how we cling to relationships, sense of self, possessions and beliefs. In the practise of mindfulness such reactions are replaced with action: one acts according to present circumstances, with understanding, kindness and compassion, without clinging to preconceived ideas and habitual reaction that may not be appropriate in the present moment. Mindfulness allows intuitive holistic understanding of traumatic situation as a sequence of innumerable interdependent processes and conditions where our efforts and intentions though by all means very important — are not the only conditions at play. The outcomes therefore cannot be controlled or ascertained. Clinging, reacting and controlling instead hinder wise actions required in traumatic situation and bring about (unnecessary) suffering.

Mindfulness practice and meditation can thus assist researchers as 'effective self-directed techniques to maintain equanimity' when faced with suffering (Berceli and Napoli 2006, 154). This has been put into practice by the lead author by regular mindfulness practise, insights and reflections on the nature of human suffering, and consequent lifestyle changes. The main skills, understanding and outcomes developed, include: a) learning to mindfully monitor internal reactions during fieldwork and data analysis, and assessing the conditions for feelings arising rather than supressing the feelings or judging the reactions; b) recognising that the most distressing (and often most consuming) parts of an interview may not be the most informative, and creating emotional equanimity (minimising arousal) during data analysis, for example, by picturing the story on a movie screen rather than letting the emotions reside in mind and body; c) creating safe spaces and time to reflect either alone or with a trusted person in a calming place, such as a favourite café or during a calming activity, such as hiking through a forest or watching the flow of waves by the beach; d) allowing the brain (and consequently body and soul) time out on a daily basis to meditate by, for example, not checking e-mails or social 
Eriksen, C. \& Ditrich, T. (2015) The relevance of mindfulness practice for trauma-exposed disaster researchers. Emotion, Space and Society, vol.17, pp.63-69

media in the evenings; and e) actively seeking out fun activities after a day in the office and during intense periods of fieldwork, as smiling and laughing have amazing healing abilities (see Mountz et al. (In Press) for more ways to create an ethics of care in academia).

Through such mindful awareness and observation of thoughts and feelings, insight is gained into their impact on body and mind, which in turn can assist thoughts and feelings to pass through without generating attachment to the pain. Rather, mental events are revealed as something akin to weather patterns that arise and fade away (Williams et al. 2007). In this way, a deeper understanding develops that 'there are no negative emotions, just unskilful ways of coping with emotions that we cannot bear' (Greenspan 2003, xiii).

\section{Conclusion}

Busch $(2011,181)$ observes that 'in Zen, you cannot really make a "wrong" decision. But you cannot make a "right" decision, either. You can only respond moment to moment in a way that feels the least harmful and deluded, the most compassionate and true'. This notion is also reflected in Solnit's (2009, 115) reflections on religion 'not as community or belief but as practice, as a craft of refining the self into something more adequate to the circumstances we face, more able to respond with grace and generosity, to achieve less temporary liberation'. Mindfulness practice and meditation can be regarded as a form of disaster preparedness for researchers who will be exposed to trauma directly or vicariously through research participants: 'equipment not only to survive but to do so with equanimity and respond with calmness and altruism to the disaster of everyday life' (Solnit 2009, 181).

In conclusion, only skilful effort keeps us 'awake'. There is real potential for disaster researchers to process vicarious trauma through mindfulness practice. Traumatic situations can be viewed as opportunities for wisdom and compassion to arise. It is here that the main benefit of mindfulness lies: it can prepare the people involved in trauma to meet it not as victims but as wise participant in the flow of the ever-changing interdependent processes that we call life. Although mindfulness is perceived today mainly as a therapeutic tool, which enhances well-being, happiness, self-fulfilment and success, the deeper significance of mindfulness should not be overlooked. Its great potential lies in 
Eriksen, C. \& Ditrich, T. (2015) The relevance of mindfulness practice for trauma-exposed disaster researchers. Emotion, Space and Society, vol.17, pp.63-69

its ability to probe into the very nature of human life, to investigate its meaning and its ethical dimensions, to open new insights into the "eternal" questions such as how to relate to life, how to approach its joys and perils, and how to face eternal change and mortality.

While mindfulness practice can result in acceptance of death, non-attachment to the idea of a permanent self, and a greater understanding of constant change (impermanence), it is important to acknowledge that the research of new applications of mindfulness is still in its early stages. Hence, this exploratory paper leaves scope and encouragement to others to expand on the relevance of mindfulness practice for trauma-exposed disaster researchers.

\section{References}

Analayo. Satipatthana: The Direct Path to Realization. Cambridge: Windhorse Publications, 2006.

Baer RA, Krietemeyer J. “Overview of mindfulness- and acceptance-based treatment approaches.” In Baer RA (ed.), Mindfulness-Based Treatment Approaches: Clinician's Guide to Evidence Base and Applications. Burlington, MA: Academic Press, 2006: 3-28.

Baer R A. Measuring mindfulness. In Mindfulness: Diverse Perspectives on its Meaning, Origins and Applications, Edited by Williams, J.M.G., Kabat-Zinn, J. Abingdon, Oxon: Routledge, 2013: 241261.

Beatson R, Murphy S, Johnson C, Pike K, Corneil W. "Exposure to duty related incident stressors in urban fire fighters and paramedics." Journal of Traumatic Stress 11 (1998): 821-7.

Beatson R, Murphy S, Johnson C, Pike K, Corneil W. "Coping responses and posttraumatic stress symptomatology in urban fire service personnel." Journal of Traumatic Stress 12 (1999): 293-307.

Berceli D, Napoli M. "A proposal for a mindfulness-based trauma prevention program for social work professionals." Complementary Health Practice Review 11 (2006): 153-65.

Bishop SR. "What do we really know about mindfulness-based stress reduction?" Psychosomatic Medicine 64 (2002): 71-83. 
Eriksen, C. \& Ditrich, T. (2015) The relevance of mindfulness practice for trauma-exposed disaster researchers. Emotion, Space and Society, vol.17, pp.63-69

Bodhi B (tr). The Connected Discourses of the Buddha: A New Translation of the Samyutta Nikaya.

Boston: Wisdom Publications, 2000.

Bodhi, B, Narada M (trs). A Comprehensive Manual of Abhidhamma: the Abhidhammattha Sangaha of Acariya Anuruddha. Kandy: Buddhist Publication Society, 1993.

Buddhaghosa. The Path of Purification (Visuddhimagga), tr. Nanamoli. Singapore: Singapore Buddhist Meditation Centre, 1956.

Caruana C. "Picking up the pieces." Family Matters (2010): 79-88.

Chopko BA, Schwartz RC. "The relation between mindfulness and posttraumatic growth: a study of first responders to trauma-inducing incidents." Journal of Mental Health Counseling 31 (2009): $363+$.

Davidson R, Kabat-Zinn J, Schumacher J, Rosenkranz M, Muller D, Santorelli SF, et al. "Alterations in brain and immune functions produced by mindfulness meditation." Psychosomatic Medicine 65 (2003): 564-70.

Ditrich T. "Mindfulness in modern Buddhism: new approaches and meanings." In One Dharma: Many Buddhist Traditions: A Festschrift in Memory of K Sri Dhammananda (1919-2006), ed.Woon Khin BL. Petaling Jaya: Buddhist Gem Fellowship, 2013.

Ehrlich G. Facing the Wave: A Journey in the Wake of the Tsunami. New York: Pantheon Books, 2013.

Eifert G, Forsyth JF. Acceptance and Commitment Therapy for Anxiety Disorders. Oakland, CA: New Harbinger Publications, 2005.

Enarson E. Women Confronting Natural Disaster: From Vulnerability to Resilience. Boulder, Colorado: Lynne Rienner Publishers, Inc., 2012.

Eriksen C. Gender and Wildfire: Landscapes of Uncertainty. New York; London: Routledge, 2014. Follette V, Palm K, Pearson A. "Mindfulness and trauma: implications for treatment." Journal of Rational-Emotive \& Cognitive-Behavior Therapy 24 (2006): 45-61.

Garland E, Gaylord S, Park J. "The role of mindfulness in positive reappraisal." EXPLORE: The Journal of Science and Healing 5 (2009): 37-44. 
Eriksen, C. \& Ditrich, T. (2015) The relevance of mindfulness practice for trauma-exposed disaster researchers. Emotion, Space and Society, vol.17, pp.63-69

Germer CK, Siegel RD, Fulton PR (eds.). Mindfulness and Psychotherapy. London: The Guilford Press, 2005.

Gethin R. The Foundations of Buddhism. Oxford; New York: Oxford University Press, 1998.

Gethin R. "On some definitions of mindfulness." In Mindfulness: Diverse Perspectives on its Meaning, Origins and Applications, Edited by Williams, J.M.G., Kabat-Zinn, J. Abingdon, Oxon: Routledge, 2013: 263-279.

Greenall PV, Marselle M. "Traumatic research: Interviewing survivors of 9/11." The Psychologist 20 (2007): 544-6.

Greenspan M. Healing through the Dark Emotions: The Wisdom of Grief, Fear, and Despair. Boston: Shambhala Publications, 2003.

Hafkenscheid A. "Event countertransference and vicarious traumatization." European Journal of Psychotherapy, Counselling and Health 7 (2005): 159-68.

Harvey P. An Introduction to Buddhism: Teachings, History and Practices. Cambridge: Cambridge University Press, 2013.

Jensen SE, McPherson GR. Living with Fire: Fire Ecology and Policy for the Twenty-first Century. Berkeley: University of California Press, 2008.

Kabat-Zinn J. "Mindfulness-based interventions in context: past, present, and future.” Clinical Psychology: Science and Practice 10 (2003): 144-156.

Kabat-Zinn J. "Some reflections on the origins of MBSR, skilful means, and the trouble with maps." In Mindfulness: Diverse Perspectives on its Meaning, Origins and Applications, Edited by Williams, J.M.G., Kabat-Zinn, J. Abingdon, Oxon: Routledge, 2013: 281-306.

Lerias D, Byrne MK. "Vicarious traumatization: symptoms and predictors." Stress and Health 19 (2003): 129-38

Lumiere LM. Healing Trauma in the Eternal Now. In The Sacred Mirror: Nondual Wisdom and Psychotherapy, Edited by Prendergast JJ, Fenner P, Krystal S, St. Paul, Minnesota: Paragon House, 2003. 
Eriksen, C. \& Ditrich, T. (2015) The relevance of mindfulness practice for trauma-exposed disaster researchers. Emotion, Space and Society, vol.17, pp.63-69

McFarlane A, Raphael B. "Ash Wednesday: the effects of a fire." Australian and New Zealand Journal of Psychiatry 18 (1984): 341-51.

McMahan DL. The Making of Buddhist Modernism. Oxford; New York: Oxford University Press, 2008.

Morton Busch C. Fire Monks: Zen Mind Meets Wildfire at the Gate of Tassajara. New York: The Penguin Press, 2011.

Mountz, A, Bonds, A, Mansfield, B, Loyd, J, Hyndman, J, Walton-Roberts, M, Basu, R, Whitson, R, Hawkins, R, Hamilton, T, Curran, W (In Press) "For Slow Scholarship: A Feminist Politics of Resistance through Collective Action in the Neoliberal University." ACME: An International Ejournal for Critical Geographies 14 (1).

Petitmengin C. "Describing one's subjective experience in the second person: an interview method for the science of consciousness." Phenomenology and the Cognitive Sciences 5 (2006): 229-69.

Pyne SJ. The Still-Burning Bush. Carlton North, Victoria: Scribe Publications Pty Ltd, 2006.

Segal ZV, Williams JMG, Teasdale, JD. Mindfulness-Based Cognitive Therapy for Depression. London: The Guilford Press. 2013.Solnit R. A Paradise Built in Hell: The Extraordinary Communities that Arise in Disaster. London: Penguin Books, 2009.

Sumedho A. The Four Noble Truths. Hemel Hempstead: Amaravati Publications, 1992.

Thomas D. "Teaching mindfulness to wildland firefighters." Fire Management Today 68 (2008): 3841.

Watson J. Marine Corps Studying How Mindfulness Meditation Can Benefit Troops. Huffington Post, 19 January 2013. Accessed 6 November 2013 [http://www.huffingtonpost.com/2013/01/22/marinecorps-mindfulness-meditation_n_2526244.html].

Weiss D, Marmar C, Metzler T, Ronfeldt H. "Predicting symptomatic distress in emergency services personnel." Journal of Consulting and Clinical Psychology 63 (1995): 361-8.

Williams M, Teasdale J, Segal Z, Kabat-Zinn J. The Mindful Way through Depression. New York: The Guilford Press, 2007.

Williams JMG, Kabat-Zinn J (eds) Mindfulness: Diverse Perspectives on its Meaning, Origins and Applications. Abingdon, Oxon: Routledge, 2013. 